\title{
Incidence and risk factors for reoperation of surgically treated urinary incontinence
}

\author{
Patrick Dällenbach • Carine Luyet • \\ Carol Jungo Nancoz $•$ Michel Boulvain
}

Received: 20 July 2012 / Accepted: 3 October 2012 / Published online: 23 October 2012

(C) The International Urogynecological Association 2012

\begin{abstract}
Introduction and hypothesis The objective of our study was to estimate the incidence and to identify the risk factors for reoperation of surgically treated stress urinary incontinence (SUI). Methods We conducted a nested case-control study among 1,132 women who underwent SUI surgery from January 1988 to June 2007. Cases $(n=35)$ were women who required reoperation for SUI following the first intervention up to December 2008. Controls $(n=89)$ were women randomly selected from the same cohort who did not require reoperation.

Results The cumulative incidence of SUI reoperation was $3.1 \%$ with a mean follow-up of 10.9 years (range 1.7-21.0). The main risk factor was the history of more than one vaginal delivery [adjusted odds ratio (OR) 3.5 ; $95 \%$ confidence interval (CI) 1.0-12.6]. The use of synthetic midurethral slings was a protective factor compared to other surgical procedures for urinary incontinence (adjusted OR $0.1 ; 95 \%$ CI $0.0-0.6$ ).
\end{abstract}

This report follows a presentation (poster and abstract) at the 41 st Annual Meeting of the International Continence Society, ICS 2011, in Glasgow and at the 2012 Annual Meeting of the Swiss Society of Gynecology and Obstetrics in Interlaken.

P. Dällenbach $(\varangle) \cdot$ C. Luyet $\cdot$ C. Jungo Nancoz

Department of Gynecology and Obstetrics,

Division of Gynecology, Urogynecology Unit,

Geneva University Hospitals,

30 Boulevard de la Cluse,

1211 Geneva 14, Switzerland

e-mail: Patrick.Dallenbach@hcuge.ch

\section{Boulvain}

Department of Gynecology and Obstetrics,

Epidemiology and Research in Obstetrics and Gynecology Unit, Geneva University Hospitals,

Geneva, Switzerland
Conclusions The risk of reoperation after SUI surgery appears to be low and associated with multiple vaginal deliveries. Synthetic slings at index surgery are associated with a lower risk of reoperation.

Keywords Female urinary incontinence $\cdot$ Incidence $\cdot$ Nested case-control study $\cdot$ Reoperation $\cdot$ Risk factors

$\begin{array}{ll}\text { Abbreviations } \\ \text { SUI } & \text { Stress urinary incontinence } \\ \text { UI } & \text { Urinary incontinence } \\ \text { MUS } & \text { Midurethral slings } \\ \text { OR } & \text { Odds ratio } \\ \text { CI } & \text { Confidence interval } \\ \text { BMI } & \text { Body mass index } \\ \text { HRT } & \text { Hormone replacement therapy } \\ \text { POP } & \text { Pelvic organ prolapse } \\ \text { ISD } & \text { Intrinsic sphincter deficiency } \\ \text { TVT } & \text { Transvaginal tape } \\ \text { TOT } & \text { Transobturator tape } \\ \text { NA } & \text { Not applicable }\end{array}$

\section{Introduction}

Urinary incontinence (UI) is a major public health problem. It is a common condition that affects almost one of two women in the USA and often impairs social, physical, and psychological well-being [1]. In Europe, it is estimated to affect up to one third of women older than 18 years. The prevalence increases with age and reaches $45 \%$ at 60 years [2]. With the aging of populations worldwide, we can expect an increase of surgical treatment for UI in the near future. The lifetime risk of undergoing UI surgery by age 80 was 
reported to be $3.6 \%$ [3]. This rate is low compared to the high prevalence and probably due to the fact that most women with UI are ashamed of their condition and do not seek help [2]. The management of recurrent UI after surgery is challenging. Repeat surgery may be associated with lower success and higher complication rate. The rate of reoperation was reported to be 8.6 and $8.8 \%$ in two recent studies in the USA and in the UK $[3,4]$. Very little is known about the factors associated with surgical failure. Old age, higher body mass index (BMI), diabetes, previous incontinence surgery, concurrent prolapse surgery, and intrinsic sphincter deficiency (ISD) are potential risk factors [5-10]. However, data vary largely between studies and results are sometimes contradictory concerning the role of risk factors such as age or BMI for example. When comparing surgical techniques, slings were protective factors compared to abdominal retropubic operations in one study, but were associated with poorer results in another one [3, 4].

The purpose of this study was to estimate the incidence and identify the risk factors for stress urinary incontinence (SUI) reoperation after previous SUI surgery.

\section{Materials and methods}

We performed a case-control study nested within a cohort. This study was approved by the Institutional Ethics Committee of the Geneva University Hospitals (protocol number $09-252 \mathrm{R})$. We identified, by using a computerized medical record database, all women $(n=1,132)$ who underwent SUI surgery in the Department of Obstetrics and Gynecology, Geneva University Hospitals, from January 1988 to June 2007. This is a teaching hospital, where all women had their operation performed either by a supervised resident in gynecological surgery or by an experienced gynecological surgeon (consultant, professor). Cases $(n=35)$ were women of this cohort who required reoperation for recurrent SUI following the first intervention through December 2008 in our institution. Because our hospital is the only public institution in the canton of Geneva and women needing a reoperation cannot be treated either outside the canton or in private institutions, we believe that most cases were identified using this strategy. Controls $(n=89)$ were patients, randomly selected from the same cohort, who did not require reoperation for SUI during the same period. We selected all cases and drew a sample of controls (two controls per case) from the hospital database which includes all women who had SUI surgery. We calculated that a sample size of 102 women with 34 cases and 68 controls had a power of $80 \%$ with a two-tailed alpha of 0.05 to demonstrate statistical significance of odds ratios (ORs) of 4 , in a plausible range of probability of exposure to a risk factor. We selected a few more controls to reach the desired number in case of unavailable medical charts.

To avoid bias in the evaluation of risk factors, data were collected from the medical charts blinded to the study group. The medical charts were photocopied and stripped of patient identity. The part concerning the first intervention was separated from that of the second in cases. One of the authors (C.L.) reviewed all of the medical charts related to the first intervention (124 surgically treated SUI) and another (P.D.) reviewed the charts related to the second intervention (35 reoperations for recurrent SUI). Variables extracted from the charts included age, weight, height, parity, number of vaginal deliveries, previous caesareans, menopausal status, hormone replacement therapy, smoking, constipation, chronic obstructive pulmonary disease, cardiovascular disease, and history of surgery for genital prolapse or UI performed outside our institution or outside the study period. All women had a standardized preoperative assessment including urodynamics in most cases and pelvic organ prolapse (POP) quantification using the Baden-Walker classification, which was the classification system used in our institution during the study period [11]. The grade of cystocele, uterine or vaginal vault prolapse, rectocele, and enterocele were identified as well as the grade of SUI according to the Ingelman-Sundberg scale [12]. The dates of SUI surgeries as well as the route (abdominal, vaginal, or laparoscopic), the techniques, and the associated interventions (POP repair, hysterectomy) were collected. The surgical techniques used in our institution for SUI over the study period included Marshall-Marchetti and Burch colposuspension as described by Hirsch et al. [13]. Women were also treated with pubovaginal slings consisting of the introduction (primarily through a vaginal approach) of a band of nonsynthetic biological material (Lyodura: lyophilized irradiated dura mater of human cadaver and pork fascia) beneath the urethra at either the bladder neck or the midurethra. The other incontinence procedures were retropubic and transobturator synthetic midurethral slings [transvaginal tape (TVT), transobturator tape (TOT)] as described by Ulmsten et al. [14] and Delorme [15]. During the study period, between 2003 and 2004, a few patients were also treated at index procedure with periurethral injections of a bulking agent (L-polylactic acid, New-Fill ${ }^{\circledR}$ ). Postoperative complications such as hematoma, fever, or vault abscess were systematically sought out.

Cases and controls were compared for the predictor variables mentioned above. Differences in proportions were tested with the chi-square test or Fisher's exact test. Differences in continuous variables were tested using the $t$ test. We performed a univariable analysis to compute the ORs for each predictor. Variables found to be statistically associated with the outcome or clinically important were then entered into logistic regression models to compute adjusted ORs. A $P$ value less than .05 was considered as statistically significant and $95 \%$ confidence intervals (CIs) were reported. Data were 
Fig. 1 Number of cases of reoperation per ongoing year

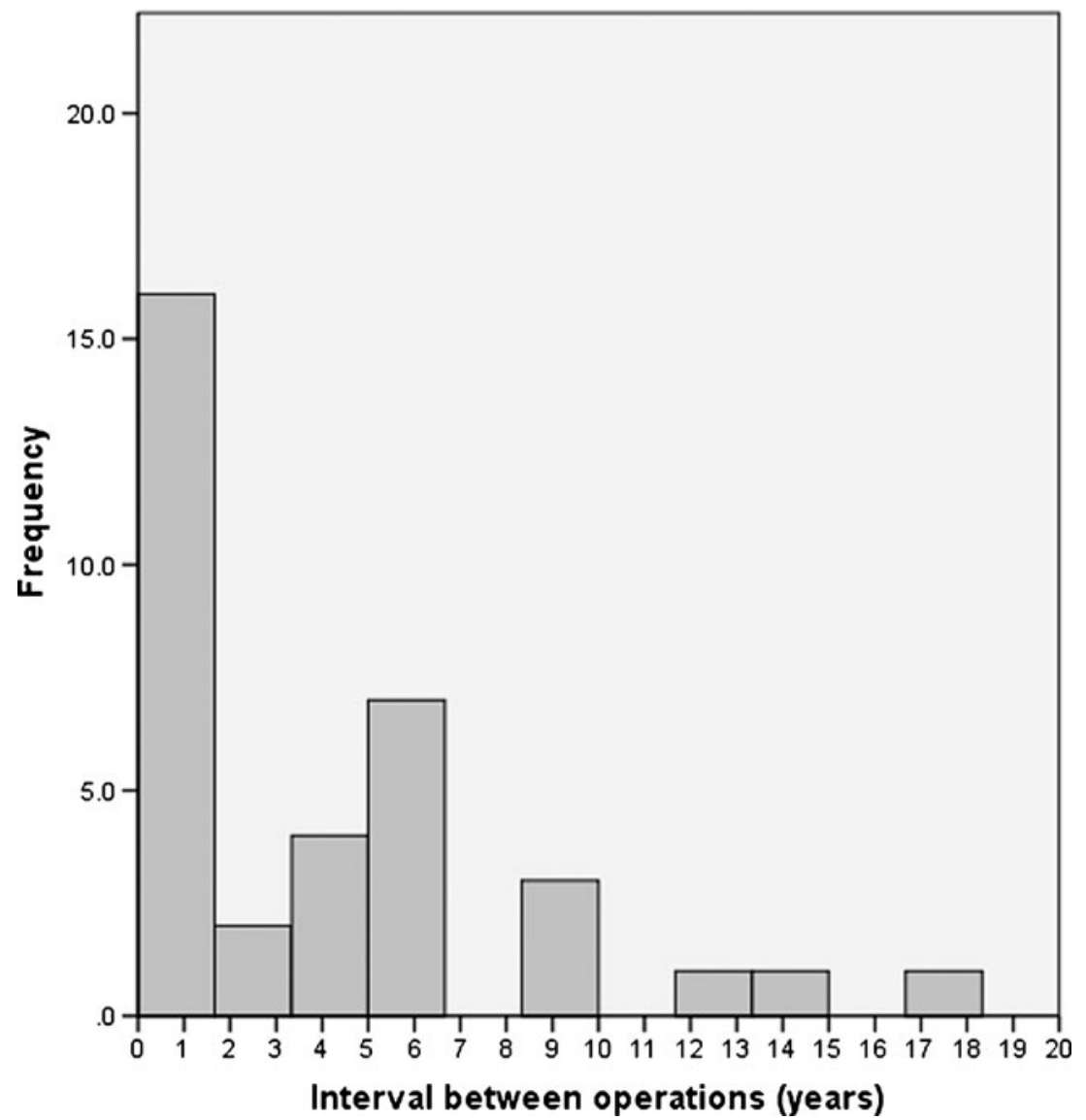

managed and analyzed with Epi Info 6 (Centers for Disease Control and Prevention, Atlanta, GA, USA) and SPSS 18.0 statistical software (SPSS Inc., Chicago, IL, USA).

\section{Results}

Between January 1988 and June 2007, 1,132 consecutive SUI surgeries were performed in our institution. Between January 1988 and December 2008, 35 women of this cohort were reoperated for subsequent SUI, presenting thereby a cumulative incidence of $3.1 \%$. The mean interval between operations was 4.1 years (range 2 months- 17.4 years) in the case group and the mean duration of follow-up was 10.9 years (range 1.7-21.0 years) in controls. The mean time interval for repeat UI surgery varied according to the type of index operation. It was $0.6(0.3-1.2)$ years in the periurethral injectables group, 3.4 (1.6-5.1) years in the synthetic midurethral slings (MUS) group, 4.5 (0.2-17.4) years in the abdominal colposuspension procedures group,

Fig. 2 Cumulative incidence of reoperation by incontinence procedure

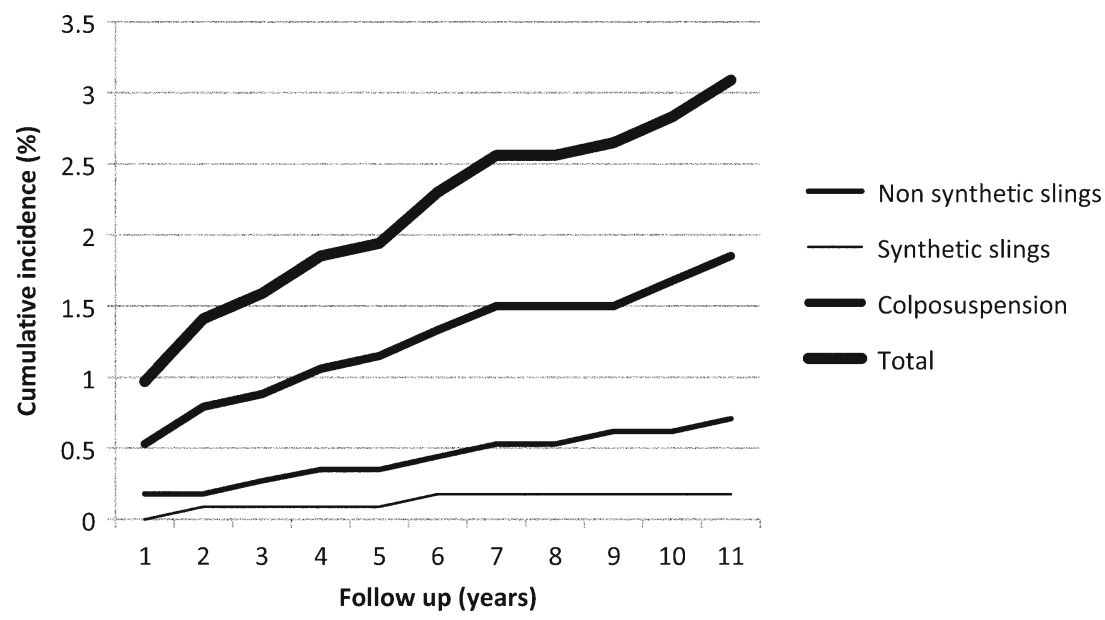


Table 1 Characteristics of the study population at first UI intervention

\begin{tabular}{llll}
\hline & $\begin{array}{l}\text { Cases } \\
(n=35)\end{array}$ & $\begin{array}{l}\text { Controls } \\
(n=89)\end{array}$ & $P$ \\
\hline Age (years), mean (SD) & $54.7(12.4)$ & $54.5(11.3)$ & 0.91 \\
Height $(\mathrm{cm})$, mean (SD) & $159.9(6.1)$ & $158.0(6.2)$ & 0.13 \\
Weight $(\mathrm{kg})$, mean (SD) & $70.8(14.4)$ & $68.2(13.6)$ & 0.34 \\
BMI $\left(\mathrm{kg} / \mathrm{m}^{2}\right)$, mean $(\mathrm{SD})$ & $27.7(5.07)$ & $27.4(5.4)$ & 0.81 \\
Menopause, $n(\%)^{\mathrm{a}}$ & $17(48.6 \%)$ & $49(55.1 \%)$ & 0.55 \\
HRT, $n(\%)^{\mathrm{a}}$ & $11(31.4 \%)$ & $21(23.6 \%)$ & 0.17 \\
Diabetes, $n(\%)^{\mathrm{a}}$ & 0 & $3(3.4 \%)$ & 0.56 \\
Asthma or COPD, $n(\%)^{\mathrm{a}}$ & 0 & $1(1.1 \%)$ & 1.0 \\
Smoking $>5$ cig./day, $n(\%)$ & $4(11.4 \%)$ & $18(20.2 \%)$ & 0.31 \\
Cardiovascular disease, $n(\%)$ & $4(11.4 \%)$ & $23(25.8 \%)$ & 0.09 \\
Constipation, $n(\%)^{\mathrm{c}}$ & $5(14.3 \%)$ & $17(19.1 \%)$ & 0.33 \\
Sexual activity, $n(\%)^{\mathrm{c}}$ & $23(65.7 \%)$ & $48(53.9 \%)$ & 0.20 \\
\hline
\end{tabular}

$P$ values are calculated with Fisher's exact test for proportions and with the $t$ test for means unless specified

$B M I$ body mass index, HRT hormone replacement therapy, COPD chronic obstructive pulmonary disease

${ }^{a}$ There was one missing value in the case group

${ }^{b}$ There was one missing value in the case group

${ }^{c}$ There were 2 and 3 missing values in the case group and 12 and 20 in the controls, with similar percentages for the 2 groups, for constipation and sexual activity, respectively

and $5.1(0.2-14.3)$ years in the nonsynthetic pubovaginal slingplasty procedures group, respectively. The number of cases per year of follow-up is shown in Fig. 1. Half of the cases were reoperated within 2 years. To account for temporal changes in the management of UI, the risk of reoperation and the contribution of each technique were evaluated for each year of follow-up (Fig. 2).

Cohort general characteristics and past medical history at index surgery are described in Tables 1 and 2 . The mean age and the mean BMI were similar in both groups. Associated POP at index surgery is described in Table 3. The stage of POP assigned according to the most severe portion of the prolapse did not differ between groups. Higher grade of SUI was not associated with an increased risk of reoperation (Table 4). There were no differences in postoperative complications between groups. One patient presented a hematoma and two patients had fever in the controls compared to none in the cases. In univariable analysis, the history of two or more vaginal deliveries was associated with a significantly increased risk of SUI reoperation (OR 3.6; $95 \%$ confidence CI 1.2-11.1; $P=0.02$ ). The history of POP repair (OR 5.33; $95 \%$ CI $0.5-60.8 ; P=0.19$ ), the presence of ISD (urethral closure pressure $\leq 20 \mathrm{cmH}_{2} \mathrm{O}$ or Valsalva leak point pressure $\leq 60 \mathrm{cmH}_{2} \mathrm{O}$ ) at urodynamics (OR 7.1; $95 \% \mathrm{CI}$ 0.7-70.6; $P=0.09$ ), abdominal colposuspension (OR 1.5; $95 \%$ CI $0.7-3.4 ; P=0.32$ ), and associated POP repair (OR $1.5 ; 95 \%$ CI $0.7-3.5 ; P=0.39$ ) or hysterectomy (OR $1.8 ; 95 \%$ CI $0.8-3.9 ; P=0.23$ ) were all associated with an increased risk of reoperation, but statistically, they were not significant (Tables 2 and 4). Statistically significant risk factors included the use of fascial slings (OR 7.2; $95 \%$ CI 1.7-29.6; $P=0.005$ ) and periurethral bulking agents $(P=0.006)$. The use of synthetic slings (transobturator or retropubic) was a protective factor (OR 0.1; $95 \%$ CI $0.0-0.4 ; P<0.001$ ) (Table 5).
Table 2 Risk factors for UI reoperation: obstetric history and previous pelvic surgery

$P$ values are calculated with Fisher's exact test. Data are presented as $n(\%)$

$O R$ odds ratio, $C I$ confidence interval, $B M I$ body mass index, $P O P$ pelvic organ prolapse

\begin{tabular}{|c|c|c|c|c|}
\hline Predictor & $\begin{array}{l}\text { Cases } \\
(n=35)\end{array}$ & $\begin{array}{l}\text { Controls } \\
(n=89)\end{array}$ & $\begin{array}{l}\text { Unadjusted OR } \\
(95 \% \mathrm{CI})\end{array}$ & $P$ \\
\hline BMI $\left(\mathrm{kg} / \mathrm{m}^{2}\right) \geq 30$ & $8(22.9 \%)$ & $29(32.6 \%)$ & $0.61(0.3-1.5)$ & 0.38 \\
\hline \multicolumn{5}{|l|}{ Parity, $n(\%)$} \\
\hline Nulliparous & $3(8.6 \%)$ & $4(4.5 \%)$ & Ref. & \\
\hline Multiparous & $32(91.4 \%)$ & $85(95.5 \%)$ & $0.5(0.1-2.4)$ & 0.40 \\
\hline \multicolumn{5}{|l|}{ Vaginal delivery } \\
\hline None or one & $4(11.4 \%)$ & $28(31.5 \%)$ & Ref. & \\
\hline Two or more & $31(88.6 \%)$ & $61(68.5 \%)$ & $3.6(1.2-11.1)$ & 0.02 \\
\hline \multicolumn{5}{|l|}{ Caesarean section } \\
\hline None & $34(97.1 \%)$ & $83(93.3 \%)$ & Ref. & \\
\hline One or more & $1(2.9 \%)$ & $6(6.7 \%)$ & $0.4(0.0-3.6)$ & 0.7 \\
\hline Previous incontinence surgery & $1(2.9 \%)$ & $3(3.4 \%)$ & $0.8(0.1-8.4)$ & 1.0 \\
\hline Previous POP surgery & $2(5.7 \%)$ & $1(1.1 \%)$ & $5.3(0.5-60.8)$ & 0.19 \\
\hline \multicolumn{5}{|c|}{ Previous POP or incontinence surgery } \\
\hline None & $32(91.4 \%)$ & $85(95.5 \%)$ & Ref. & \\
\hline One or more & $3(8.6 \%)$ & $4(4.5 \%)$ & $2.0(0.4-9.4)$ & 0.40 \\
\hline Previous hysterectomy & $5(14.3 \%)$ & $12(13.5 \%)$ & $1.1(0.4-3.3)$ & 1.0 \\
\hline None & $30(85.7 \%)$ & $77(86.5 \%)$ & Ref. & \\
\hline
\end{tabular}


Table 3 Description of preoperative POP at first intervention

\begin{tabular}{lllr}
\hline & Cases $(n=35)$ & Controls $(n=89)$ & $\begin{array}{c}\text { Unadjusted OR } \\
(95 \% \text { CI })\end{array}$ \\
\hline Any POP at first intervention & & $75(84.3 \%)$ & $3.1(0.7-14.3)$ \\
None & $33(94.3 \%)$ & $14(15.7 \%)$ & $\begin{array}{l}P \text { Ref. } \\
\text { POP grade 2, 3, and 4 }\end{array}$ \\
POP grade 0 and 1 & $2(5.7 \%)$ & $47(52.8 \%)$ & $1.2(0.5-2.6)$ \\
Anterior compartment prolapse grade 3 and 4 & $15(57.1 \%)$ & $42(47.2 \%)$ & Ref. \\
Anterior compartment prolapse grade 2 or less & $7(20 \%)$ & $9(10.1 \%)$ & $2.2(0.8-6.5)$ \\
\end{tabular}

$P$ values are calculated with Fisher's exact test. Data are presented as $n(\%)$

$O R$ odds ratio, $C I$ confidence interval

In multivariable analysis (Table 6), synthetic MUS remained a protective factor compared to abdominal colposuspension procedures. History of two or more vaginal deliveries still increased the risk of reoperation for SUI. The association between previous POP repair and an increased risk of reoperation for UI remained high although not statistically significant.

\section{Discussion}

Our study suggests that the risk of reoperation after SUI surgery is low and associated with multiple vaginal deliveries. Synthetic midurethral slings are associated with a lower rate of reoperation compared to abdominal colposuspension procedures or traditional pubovaginal biological slings.

We systematically searched MEDLINE (search terms: "reoperation for surgically treated/managed stress urinary incontinence, risk factors of repeat urinary incontinence surgery, follow-up studies," all languages, from 1966 to 2012) and found few studies reporting the incidence of reoperation for recurrent SUI. Most authors measured a combined risk of reoperation for surgically treated POP and UI between 13 and $29 \%[16,17]$. We found two studies reporting reoperation rates for UI alone of 8.6 and $8.8 \%$, respectively, which is higher than our cumulative incidence of $3.1 \%[3,4]$. The incidence is influenced by access to medical care and financial considerations, rendering comparisons between different populations difficult. The difference from the higher rates reported in the medical literature may theoretically be explained by operations performed outside our university clinic and not included in our cohort, resulting in an underestimation of the real incidence. However, that number is probably low as our clinic is the only public institution in the canton of Geneva. Women followed in public hospitals in Switzerland rarely go to private clinics due to their lack of private health insurance coverage, and Swiss health insurances only exceptionally permit a patient to be operated in another canton or country. We chose to evaluate surgically treated recurrent SUI, as it represents the severe end of the clinical spectrum. The incidence of SUI recurrence is probably higher, but most women may find it tolerable and therefore do not seek surgery.

Table 4 Risk of reoperation according to preoperative grade of SUI and urodynamic measures

\begin{tabular}{|c|c|c|c|c|}
\hline Age (years) & Cases $(n=35)$ & Controls $(n=89)$ & $\begin{array}{l}\text { Unadjusted OR } \\
(95 \% \mathrm{CI})\end{array}$ & $P$ \\
\hline Grade 1 & $11(31.4 \%)$ & $24(27 \%)$ & Ref. & \\
\hline Grade 2 or 3 & $24(68.6 \%)$ & $65(73 \%)$ & $0.8(0.3-1.9)$ & 0.66 \\
\hline Grade 3 & $3(8.6 \%)$ & $5(5.6 \%)$ & $1.58(0.4-7.0)$ & 0.69 \\
\hline ISD $\left(\mathrm{UCP} \leq 20 \mathrm{cmH}_{2} \mathrm{O} \text { or } \mathrm{VLPP} \leq 60 \mathrm{cmH}_{2} \mathrm{O}\right)^{\mathrm{a}}$ & $3(8.8 \%)$ & $1(1.4 \%)$ & $7.1(0.7-70.6)$ & 0.09 \\
\hline Transmission factors $\leq 50 \%{ }^{\mathrm{b}}$ & $4(14.3 \%)$ & $17(23.9 \%)$ & $0.5(0.2-1.7)$ & 0.42 \\
\hline Associated urge incontinence ${ }^{c}$ & $13(37.1 \%)$ & $27(32.9 \%)$ & $1.2(0.5-2.8)$ & 0.68 \\
\hline
\end{tabular}

$P$ values are calculated with Fisher's exact test. Data are presented as $n(\%)$.

$O R$ odds ratio, $C I$ confidence interval, ISD intrinsic sphincter deficiency, $U C P$ urethral closure pressure, VLPP Valsalva leak point pressure

${ }^{a}$ Six patients in the control group did not have preoperative urodynamics

${ }^{\mathrm{b}}$ Seven missing values in cases and 18 in controls

${ }^{\mathrm{c}}$ Seven missing values in the controls 
Table 5 Type of intervention

\begin{tabular}{|c|c|c|c|c|}
\hline Variable & Cases $(n=35)$ & Controls $(n=89)$ & $\begin{array}{l}\text { Unadjusted OR } \\
\text { (CI 95\%) }\end{array}$ & $P$ \\
\hline Synthetic slingplasty (TVT/TOT) & $2(5.7 \%)$ & $34(38.2 \%)$ & $0.1(0.0-0.4)$ & $<0.001$ \\
\hline Nonsynthetic pubovaginal slingplasty & $8(22.9 \%)$ & $11(12.4 \%)$ & $2.1(0.8-5.8)$ & 0.17 \\
\hline Abdominal colposuspension (Marshall-Marchetti or Burch) & $21(60 \%)$ & $44(49 \%)$ & $1.5(0.7-3.4)$ & 0.32 \\
\hline Periurethral bulking agent & 4 & 0 & NA & 0.006 \\
\hline Associated POP repair & $13(37.1 \%)$ & $25(28.1 \%)$ & $1.5(0.7-3.5)$ & 0.39 \\
\hline Anterior colporrhaphy & $8(22.9 \%)$ & $20(22.5 \%)$ & $1.0(0.4-2.6)$ & 1.0 \\
\hline Posterior colporrhaphy & $5(14.3 \%)$ & $8(9.0 \%)$ & $1.7(0.5-5.6)$ & 0.52 \\
\hline Enterocele repair & $1(2.9 \%)$ & $1(1.1 \%)$ & $2.6(0.2-42.6)$ & 0.49 \\
\hline Vault suspension & $1(2.9 \%)$ & $3(3.4 \%)$ & $0.8(0.1-8.4)$ & 1.0 \\
\hline Associated hysterectomy & $21(60 \%)$ & $41(46.1 \%)$ & $1.8(0.8-3.9)$ & 0.23 \\
\hline
\end{tabular}

Data are presented as $n(\%) . P$ values are calculated with Fisher's exact test unless specified

$O R$ odds ratio, $C I$ confidence interval, TVT transvaginal tape, TOT transobturator tape, $P O P$ pelvic organ prolapse, $N A$ not applicable

Little is known about the risk factors that prevent or favor recurrence and consecutive reoperation for SUI. Corroborating our previous report which focused on reoperation for POP surgery, we found that factors associated with the weakening of the pelvic floor (previous POP or incontinence surgery, associated POP surgery, or hysterectomy) were associated with an increased risk of reoperation [18]. Results were however not statistically significant, probably due to the small number of cases. Daneshgari et al., in a case-control study, also found an increased risk of recurrent SUI surgery in women with concomitant POP or pelvic floor repair [6]. In their study, age and BMI were similar between groups and did not influence the reoperation rate, which is similar to our findings.

An important finding of our study was that the number of vaginal deliveries before initial surgery increased the risk of reoperation. We hypothesize that each vaginal delivery weakens the pelvic floor through muscular, fascia, and nerve

Table 6 Risk factors for UI reoperation: multivariable analysis. ORs and $95 \%$ CIs adjusted for the other factors in the model

\begin{tabular}{lll}
\hline Risk factor & $\begin{array}{l}\text { Adjusted OR } \\
(95 \% \mathrm{CI})\end{array}$ & $P$ \\
\hline Age & $1.0(1.0-1.1)$ & 0.63 \\
BMI & $1.0(1.0-1.0)$ & 0.58 \\
History of two or more vaginal deliveries & $3.5(1.0-12.6)$ & 0.05 \\
History of POP repair & $10.5(0.6-175.2)$ & 0.10 \\
Type of surgery & & \\
Colposuspension (Burch, Marshall-Marchetti) & Ref. & \\
Synthetic slings (TVT, TOT) & $0.1(0.0-0.6)$ & 0.01 \\
Nonsynthetic slings & $2.1(0.7-6.2)$ & 0.17 \\
\hline
\end{tabular}

$P$ values are calculated with the chi-square test unless specified. Each $\mathrm{OR}$ and $95 \% \mathrm{CI}$ is adjusted for all other covariates listed in this table

$O R$ odds ratio, $C I$ confidence interval, $B M I$ body mass index, $P O P$ pelvic organ prolapse, $T V T$ transvaginal tape, TOT transobturator tape damage. Therefore, surgical procedures which may not restore stable and long-lasting suburethral support are more likely to fail. To limit the risk of reoperation, it might be important to use a synthetic mesh to reinforce suburethral support rather than biological material or sutures attached to an already weakened pelvic floor, especially in case of multiple vaginal deliveries. Similarly, in a large longitudinal study, Abdel-Fattah et al. found that having more than two vaginal deliveries was an independent risk factor for POP/UI surgery [3]. However, contrary to our findings, it was not associated with UI reoperation; the risk was slightly increased in those women with more than two vaginal deliveries, but was not statistically significant.

In accordance with previous reports, ISD was associated with an increased rate of reoperation in our study, although the result was not statistically significant [5]. We hypothesize that nerve damage occurring during vaginal delivery may increase the risk of a hypotonic urethra, thus increasing the risk of UI surgery failure. Fialkow et al. in a large cohort study found that women undergoing the Burch technique had a lower reoperation rate than women undergoing slings [4]. However, in their study, slings were a heterogeneous group combining native, biological, and synthetic slings and the proportion of each was unknown. We hypothesize that most of the slings described in this study were probably nonsynthetic. Abdel-Fattah et al. in a recent study also found a lower reoperation rate for MUS (3.2 \%) compared to abdominal retropubic surgery $(10.7 \%)[3]$.

It can be argued that the use of synthetic midurethral slings is a newer procedure and has not been used in surgical practice for as long as abdominal colposuspension procedures and therefore the detected reduced risk may be subject to bias. However, the mean interval for repeat UI surgery was 3.4 years following synthetic slings compared to 4.5 years following abdominal colposuspension procedures, and we believe that repeat surgery following synthetic MUS is likely to have been captured within the time frame of this 
study. Similarly, in the Abdel-Fattah et al. study, repeat UI surgery also occurred earlier in the MUS group compared to the retropubic abdominal procedures group [3].

The use of periurethral injectables was associated with an increased risk of reoperation in our study which is comparable to the findings reported by Adel Fattah et al. However, the number of patients treated with this method was very small and it is difficult to draw any firm conclusions. In contrast to the findings of previous reports, diabetes was not a significant risk factor in our study. However, the numbers were too small to show any effect of this factor on the risk of reoperation, and we thereby once again cannot draw any firm conclusions $[5,6]$.

The limitations of this study were the small number of cases, thus rendering the multivariable analysis difficult to interpret. The power of the study was also not sufficient to show statistically significant differences for some of the risk factors such as history of previous POP repair or ISD at urodynamics. However, risk factors evaluated in the univariable analysis and in the multivariable model showed the same magnitude of association, although this was not statistically significant; we believe this tendency to be of clinical significance.

The strength of this study was the availability of a continuously updated computerized register, which allowed us to identify cases and controls in the same large cohort with a long follow-up. Another strength was the preoperative standardized assessment, including urodynamics in most cases and POP quantification. The assessment of SUI was more reliable than in studies using questionnaires.

Based on our data and recent studies, we believe the risk of reoperation for recurrence after SUI surgery to be between 3 and $9 \%$. It might be important to use synthetic suburethral slings at index surgery, especially in women with a history of multiple vaginal deliveries.

Acknowledgments The authors thank Dr. Dimitrios Sourlas for his help in collecting the data, and Dr. M Francis Dällenbach for correcting the English. This study was conducted with the support of the Department of Gynecology and Obstetrics of the University of Geneva.

Conflicts of interest None.

\section{References}

1. Markland AD, Richter HE, Fwu CW, Eggers P, Kusek JW (2011) Prevalence and trends of urinary incontinence in adults in the United States, 2001 to 2008. J Urol 186:589-593
2. Hunskaar S, Lose G, Sykes D, Voss S (2004) The prevalence of urinary incontinence in women in four European countries. BJU Int 93:324-330

3. Abdel-Fattah M, Familusi A, Fielding S, Ford J, Bhattacharya S (2011) Primary and repeat surgical treatment for female pelvic organ prolapse and incontinence in parous women in the UK: a register linkage study. BMJ Open 1:e000206

4. Fialkow M, Symons RG, Flum D (2008) Reoperation for urinary incontinence. Am J Obstet Gynecol 199(5):546.e1-546.e8

5. Stav K, Dwyer PL, Rosamilia A, Schierlitz L, Lim YN, Lee J (2010) Risk factors of treatment failure of midurethral sling procedures for women with urinary stress incontinence. Int Urogynecol J 21:149-155

6. Daneshgari F, Moore C, Frinjari H, Babineau D (2006) Patient related risk factors for recurrent stress urinary incontinence surgery in women treated at a tertiary care center. J Urol 176:1493-1499

7. Houwert RM, Venema PL, Aquarius AE, Bruinse HW, Roovers JP, Vervest HA (2009) Risk factors for failure of retropubic and transobturator midurethral slings. Am J Obstet Gynecol 201(2):202.e1202.e8

8. Richter HE, Goode PS, Brubaker L, Zyczynski H, Stoddard AM, Dandreo KJ, Norton PA (2008) Two-year outcomes after surgery for stress urinary incontinence in older compared with younger women. Obstet Gynecol 112:621-629

9. Hellberg D, Holmgren C, Lanner L, Nilsson S (2007) The very obese woman and the very old woman: tension-free vaginal tape for the treatment of stress urinary incontinence. Int Urogynecol J Pelvic Floor Dysfunct 18:423-429

10. Barber MD, Kleeman S, Karram MM, Paraiso MF, Ellerkmann M, Vasavada S, Walters MD (2008) Risk factors associated with failure 1 year after retropubic or transobturator midurethral slings. Am J Obstet Gynecol 199(6):666.e1-666.e7

11. Baden W, Walker T (1992) Surgical repair of vaginal defects. Lippincott, Philadelphia

12. Ingelman-Sundberg A, Ulmsten U (1983) Surgical treatment of female urinary stress incontinence. Contrib Gynecol Obstet 10:5169

13. Hirsch H, Käser O, Iklé F (1997) Atlas of gynecologic surgery. Thieme, New York

14. Ulmsten U, Henriksson L, Johnson P, Varhos G (1996) An ambulatory surgical procedure under local anesthesia for treatment of female urinary incontinence. Int Urogynecol J Pelvic Floor Dysfunct $7: 81-85$, discussion $85-86$

15. Delorme E (2001) Transobturator urethral suspension: miniinvasive procedure in the treatment of stress urinary incontinence in women. Prog Urol 11:1306-1313

16. Olsen AL, Smith VJ, Bergstrom JO, Colling JC, Clark AL (1997) Epidemiology of surgically managed pelvic organ prolapse and urinary incontinence. Obstet Gynecol 89:501-506

17. Denman MA, Gregory WT, Boyles SH, Smith V, Edwards SR, Clark AL (2008) Reoperation 10 years after surgically managed pelvic organ prolapse and urinary incontinence. Am J Obstet Gynecol 198(5):555.e1-555.e5

18. Dallenbach P, Jungo Nancoz C, Eperon I, Dubuisson JB, Boulvain M (2012) Incidence and risk factors for reoperation of surgically treated pelvic organ prolapse. Int Urogynecol J $23: 35-41$ 